Número Extraordinario. p.p. 153-161

Memorias del Primer encuentro ambiental Universidad, ambiente y sustentabilidad: experiencias y prácticas.

\title{
LEGISLACIÓN Y REGLAMENTACIÓN PARA EL USO DEL ASBESTO: NORMATIVIDAD Y PROHIBICIÓN
}

\author{
Cristian Hernando Rivera Moyano ${ }^{1}$ \\ Wilmar David Díaz Ramírez ${ }^{1}$
}

\section{Resumen}

El presente artículo muestra una investigación realizada frente a las leyes de protección y manejo del asbesto, así como los diversos proyectos de ley realizados en Colombia para la prohibición del mismo. Dichas investigaciones se desarrollaron durante el año 2016 al mismo tiempo que se proponía por sexta vez, una ley cuyo objetivo era el de prohibir el uso de esta fibra en Colombia. El debate se desarrolló en la comisión séptima del senado y en éste se tuvo como referente la prohibición que yace sobre este material en más de 55 países, sin embargo, el proyecto de ley no contó con suficiente respaldo y se denegó una vez más.

En Colombia, se calcula que mueren cerca de 320 personas al año por causa de alguna enfermedad relacionada con el asbesto, por ello se busca conocer cuáles son las leyes y derechos que cubren a las personas afectas, así como a quienes tienen contacto indirecto con esta fibra mortal.

Palabras Claves: Asbesto, Prohibición, Regulación, Colombia.

\section{Abstract}

The present article shows a research carried out in front of the laws of protection and management of asbestos, as well as the various bills made in Colombia for the prohibition of asbestos. These investigations were carried out during the year 2016 at the same time as it was proposed for the sixth time, a law whose objective was to prohibit the use of this fiber in Colombia. The debate took place in the seventh commission of the Senate and in this one had as reference the prohibition that lies on this material in more than 55 countries, nevertheless, the bill did not count on enough support in Senate and was denied once again.

Universidad Pedagógica Nacional, Estudiantes de Licenciatura en Química, SISMA Semillero de investigación en salud y medio ambiente. 
Número Extraordinario. p.p. 153-161

Memorias del Primer encuentro ambiental Universidad, ambiente y sustentabilidad: experiencias y prácticas.

In Colombia, it is estimated that about 320 people die each year from an asbestos-related disease. This is why it seeks to know the laws and rights that cover affected persons, as well as those who have indirect contact with this disease Deadly fiber.

Key Word: Asbestos, Prohibition, Regulation, Colombia.

\section{INTRODUCCIÓN}

El asbesto es un mineral de origen natural presente en el medio ambiente. Este mineral se encuentra en pequeñas partículas las cuales tienen propiedades físicas y químicas que le dan versatilidad, tales como: gran resistencia al calor y al fuego, fácil maleabilidad, resistencia a sustancias químicas, baja conductividad eléctrica, entre otras. (Montes, I., et al., 2005)

Por las razones mencionadas, el asbesto se constituye como un mineral muy apetecido por diferentes industrias, especialmente la de la construcción, ya que al tener todas estas propiedades se convierte en un mineral muy versátil; por ejemplo, en el reforzamiento del cemento y el plástico, aislante en techos, material incombustible para la absorción del sonido, etc., reduciendo de esta forma la inversión que tienen que hacer estas mismas empresas en la compra de materiales adicionales. (GITICSA, 2009)

Por otra parte, alrededor de los años 70, se comenzó a descubrir que el asbesto, además de tener los beneficios en la industria ya señalados, tenía también muchos perjuicios especialmente para la salud. (Gromicko, N., Ward, E.)

Las investigaciones dieron a conocer una revelación muy importante con respecto al asbesto y es que se trata de un material altamente peligroso. (Driscoll,T., et al., 2005) Se afirma que su contacto con los humanos, es el causante de enfermedades pulmonares tales como asbestosis, o el engrosamiento de la pleura pulmonar, en trabajadores de la industria de asbesto o la comunidad que reside cerca de las zonas industriales donde es utilizado como materia prima o alrededor de los sitios de explotación de dicho material. 
Número Extraordinario. p.p. 153-161

\section{Memorias del Primer encuentro ambiental Universidad, ambiente y sustentabilidad: experiencias y prácticas.}

Pero esto no es todo. Lo más peligroso del asbesto, es que es un mineral cancerígeno. Una sola partícula del material que logre entrar a los pulmones puede generar desde un mesotelioma (cáncer poco común del revestimiento delgado del pecho y del abdomen), hasta un cáncer de pulmón. $Y$ dado que estos tipos de cáncer tienen un periodo de incubación largo, la detección de la enfermedad, en la mayoría de los casos, no se logra a tiempo, causando, además del sufrimiento por la enfermedad, la muerte de los afectados. (OMS, 2015)

No obstante, y a pesar de los peligros que conlleva su uso, el asbesto en muchos países es completamente legal, en diferentes naciones alrededor del mundo como Sudáfrica, Nueva Zelanda, Paraguay, o inclusive grandes potencias como Rusia, no existe ningún tipo de ley que prohíba el uso de este material. Pero no son solo ellos, la realidad es que la mayoría de países del mundo ignoran el peligro del asbesto, ya que solamente 56 países del mundo lo prohíben (ElTiempo, Redacciones, 1999)

\section{OBJETIVOS}

General: Analizar la legislación y/o reglamentación, respecto al uso del asbesto tanto en el país, como en América Latina y el resto del mundo para comprender por qué no se ha tomado una decisión definitiva en nuestro país.

Específicos:

- Estudiar los distintos proyectos de ley que han sido propuestos para la prohibición del uso de asbesto.

- Establecer cuáles son los motivos que motivan a la falta de leyes respecto al uso del mineral en estudio.

- Conocer y estudiar como fue el proceso de prohibición en otras partes del mundo.

\section{MARCO TEÓRICO}

El asbesto y su prohibición en el mundo: Sólo contadas excepciones, como los países miembros de la Unión Europea, le han dicho NO al uso de este peligroso material; y lo han hecho de forma definitiva, ya que en 
Número Extraordinario. p.p. 153-161

Memorias del Primer encuentro ambiental Universidad, ambiente y sustentabilidad: experiencias y prácticas.

dichos países el uso del asbesto (o cualquier derivado de éste) está completamente prohibido.

Entre los países que han prohibido el uso del asbesto se puede destacar a: Alemania, Arabia Saudita, Argentina, Australia, Bélgica, Chile, Dinamarca, Emiratos Árabes, Eslovenia, España, Finlandia, Francia, Gran Bretaña, Grecia, Holanda, Islandia, Italia, Luxemburgo, Noruega, Nueva Zelanda, Polonia, Portugal, República Checa, Suecia, Suiza, Uruguay, entre otros. Además, países como Croacia, Taiwán, Israel y Singapur están en proceso de su prohibición. (AyudaMesotelioma A. C., 2011)

Países como España se han adelantado al mundo con respecto a este tema, prohibiendo el asbesto desde hace ya tres décadas. Sin embargo, hay otros como Brasil que aún siguen defendiendo su uso, bajo la excusa del uso responsable o la afectación a la economía nacional, aun sabiendo que a nivel mundial se han dado diferentes lineamientos, plazos y esperas para que las empresas que hay en dichas naciones encuentren la manera de trabajar sin asbestos, o que hallen un material para reemplazarlo. Pero en estos estados parece que pesan más los intereses económicos que las vidas humanas. Sin embargo, también hay que resaltar el accionar que tuvieron países como Canadá respecto a este tema, ya que en poco tiempo pasó de ser uno de los más emblemáticos defensores del asbesto, a dar comienzo a programas de desmonte y prohibición del mismo. (Proyecto de Ley 97, 2015)

El asbesto está prohibido por medio del Convenio de Róterdam. El Convenio de Rotterdam se hizo para la aplicación del procedimiento de consentimiento fundamentado previo (CFP) a ciertos plaguicidas y productos químicos peligrosos objeto de comercio internacional. Fue adoptado el 10 de septiembre de 1998, en una reunión de Países Plenipotenciarios de las Naciones Unidas, celebrada en Rotterdam, Holanda. El Convenio entró en vigor el 24 de febrero de 2004. Este Convenio fue firmado por más de cien países. (Chávez, 2009)

La COMISIÓN TÉCNICA DE LA UNIÓN EUROPEA, el 1 de enero del 2005 aprobó la prohibición de todo tipo de asbesto para todos los países que aún no lo han prohibido, y en el año 2006 inicio una dura campaña contra éste, bajo el contundente lema “¡El asbesto es mortal!” (Montes, I., et al., 2005) 
Número Extraordinario. p.p. 153-161

\begin{abstract}
Memorias del Primer encuentro ambiental Universidad, ambiente y sustentabilidad: experiencias y prácticas.
\end{abstract}

América y sus leyes contra el asbesto: Por su parte, en América Latina solamente cuatro países han establecido leyes para prohibir el uso del asbesto. Estos países son: Argentina, Chile, Uruguay y Honduras. Han prohibido el asbesto como tal y todos sus derivados.

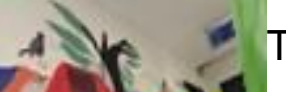

También países como Estados Unidos, han creado algunas leyes para reglamentar su uso y disminuir el impacto a la salud humana de este mineral. El EPA (Environmental Protection Agency) ha dictaminado que por ejemplo, el uso del asbesto queda prohibido para compuestos, para la reparación de tabla roca o cartón-yeso y en chimeneas de gas. (Montes, I., et al., 2005)

Argentina fue el primer estado que prohibió el uso de anfíboles en el año 2000, y el uso y la importación del uso del crisolito. Los anfíboles son un conjunto de minerales de la clase de los silicatos, grupo inosilicatos. Químicamente son metasilicatos de calcio, magnesio y hierro. Son minerales fibrosos. En donde se clasifica el asbesto, como un mineral fibroso. (Hess, A., 2000) En el año 2001 por medio del decreto 656 del Ministerio de Salud, Chile prohíbe por completo toda la producción, distribución y uso de cualquier tipo de asbesto, así como también todo material que lo contenga (Ley $N^{\circ} 656,2000$ ) mientras que en Uruguay se implementó esta misma política un año después, al restringir su fabricación e importación. (dec. $n^{\circ}$ 154, 2002) Honduras, por su parte, prohibió dos años más tarde el uso de productos que contengan crisolito, amosita, entre otros; así como su respectiva fabricación y/o comercialización. (Acuerdo no 032-2004, 2004)

Legislación en Colombia: En lo que se refiere a Colombia, en la actualidad hay muchas campañas en contra del uso de asbesto, las cuales buscan su prohibición. Se calcula que mueren alrededor de 320 personas al año a causa de alguna enfermedad relacionada con el asbesto. (Proyecto de Ley 97, 2015)

Sin embargo, y a pesar de esto, en Colombia es inexistente la ley que prohíbe el uso del asbesto. La regulación del uso del asbesto en nuestro país solamente se limita al Convenio Internacional de la OIT, el cual estipula que se debe proteger al trabajador, en su labor, del asbesto. 
Número Extraordinario. p.p. 153-161

Memorias del Primer encuentro ambiental Universidad, ambiente y sustentabilidad: experiencias y prácticas.

El Ministerio de Trabajo creó en 1996 la Comisión Nacional de Salud del Asbesto y otras fibras. Por medio de la resolución 935 del 2001, el mismo Ministerio produjo el Reglamento de Higiene y Seguridad del Crisolito y otras fibras de uso similar en ámbitos laborales. (EITiempo, 2014)

En los últimos 9 años se han radicado 6 proyectos de ley para prohibir el asbesto, sin embargo ninguno de estos proyectos ha sido fructífero, ya que todos han sido denegados por parte del senado. (Proyecto de Ley 97, 2015)

En las diversas oportunidades en que se ha intentado crear un proyecto de ley para controlar el uso asbesto, se han presentado situaciones difusas que no permiten llegar a la prohibición del mismo. En tres de esas oportunidades la misma persona que presenta el proyecto termina retirándolo, y en otras ocasiones, ni siquiera se llega tener un debate respecto al tema.

Como dato adicional, se sabe que la principal empresa que maneja el uso de asbesto en el país, ETERNIT, comercializa productos con asbesto solo dentro del país, ya que en la mayoría de casos, los productos que exportan, son elaborados sin este material. (ElTiempo, Redacciones, 1999)

\section{METODOLOGIA}

La metodología de este trabajo comenzó con la investigación del material, sus propiedades y los peligros que generan en el cuerpo de una persona. Después se centró a un estudio jurídico de asbesto en donde se buscaba conocer las leyes y precauciones que se han generado a nivel internacional por la Organización Mundial de la Salud (OMS) y la Organización Internacional del Trabajo (OIT). Y ver cómo y desde cuando Colombia ha actuado respecto a las pronunciaciones de estas recomendaciones. (Accinelli, R., López, L., 2005)

Por último, se realizó una búsqueda de los proyectos de ley que se han radicado en el Congreso en Colombia para dejar la explotación y el uso del asbesto en las industrias y fábricas, y por qué ninguno fue aceptado.

Esta investigación busca que se conozca cuáles son las medidas de precaución que se tiene en el país sobre el uso del asbesto y por qué se ha intentado retirar a éste de uso industrial. 
Número Extraordinario. p.p. 153-161

Memorias del Primer encuentro ambiental Universidad, ambiente y sustentabilidad: experiencias y prácticas.

Nosotros somos un grupo de investigación perteneciente a la Universidad Pedagógica.

\section{RESULTADOS}

Durante el ejercicio investigativo, en torno a la parte legislativa, hemos hallado lo siguiente:

El en año 1886 la Organización Internacional del Trabajo (OIT) creó el convenio sobre el asbesto numero 162 (C162), cuyo objetivo era garantizar la salud y seguridad de los trabajadores que manipularan el asbesto. En Colombia, es solo desde el año 1998 que este convenio fue implementado en la reglamentación colombiana.

- En la actualidad ya hay más de 50 países que prohíben el uso de asbesto, incluyendo toda la Unión Europea. Y en la región solamente 4 países lo han prohibido. Estos países son: Argentina, Chile, Honduras y Uruguay. Por otra parte, Brasil apoya el uso del asbesto.

2 - La Organización Mundial de la Salud afirma que todo tipo de amianto produce cáncer de pulmón, mesotelioma, cáncer de laringe y de ovarios y asbestosis (fibrosis de los pulmones). (OMS, 2015)

- Se pudo evidenciar que el asbesto ya cuenta con materiales homólogos que reemplazan su uso sin embargo, la implementación de los mismos aumenta el costo de la producción por lo que las empresas prefieren seguir utilizando esta fibra dentro de su cadena de producción. Lo más insólito respecto al tema es que éstas mismas empresas, a la hora de tener que exportar sus productos a países donde existe la reglamentación que prohíbe el uso de éste material y sus derivados, si pueden realizar la producción utilizando otros materiales. Uno de los casos que más llama la atención, respecto a la particularidad descrita, es el caso de Eternit. Anexo a esto, en la mina de extracción de asbesto, ubicada en el municipio de Campamento, Antioquia, generalmente se escuchan bastantes testimonios de sus habitantes, los cuales declaran que han sufrido diversas afectaciones en su salud por la constante cercanía que tienen con el material. (ElTiempo, 2014)

- En Colombia se han radicado 6 proyectos de ley, los cuales buscan la prohibición del asbesto en el país. De 2007 a la actualidad, cada uno de estos proyectos ha sido denegado por diversas razones que incluyen el hoy político del país, generando consigo que estos proyectos de ley sean archivados sin discusión en el senado o simplemente son retirados por los mismos impulsadores. 
Número Extraordinario. p.p. 153-161

Memorias del Primer encuentro ambiental Universidad, ambiente y sustentabilidad: experiencias y prácticas.

\section{CONCLUSIONES}

El asbesto, al ser un mineral tan peligroso, merece ser regulado por parte del Estado. Se debe vencer los intereses políticos y económicos de personas, empresarios, monopolios e industrias, y se debe pensar más en la salud y la vida de cientos de colombianos que son afectados diariamente por este peligroso material.

- A las empresas que usan el asbesto en sus diferentes producciones, les importa más la economía de sus respectivos negocios, que la vida de las personas, ya que se ha demostrado que tanto sus trabajadores, como las personas que viven cerca de dichas empresas, sufren de graves enfermedades respiratorias, producto de la constante exposición a este material, sin embargo y a pesar de tener conocimiento de que hay formas de reemplazar el asbesto, estas se reúsan a hacerlo, defendiendo su uso de todas la maneras posibles.

- Las autoridades superiores del país y los diferentes entes políticos que lo dirigen, deberían prestar más atención a este tipo de problemáticas sociales, ya que si bien no es el problema principal que tiene el país, cada vez son más los colombianos que se ven afectados por esta clase de fenómenos, sin que el Estado haga nada para solucionar el problema.

- El asbesto es un material muy cancerígeno que cada vez mata más personas y es hora que la legislación del país haga presencia respecto a este tema.

\section{REFERENCIAS BIBLIOGRAFICAS}

Accinelli, R., López, L. (2005). Situación de la prohibición del uso de asbesto en España y Latinoamérica. Obtenido de http://www.archbronconeumol.org/es/situacion-prohibicion-del-usoasbesto/articulo/S0300289613003372/

Acuerdo no 032-2004, 032 (La constitucion de Honduras 2004).

AyudaMesotelioma A. C. (6 de Enero de 2011). Asbesto en el Mundo.

Obtenido de http://mesotelioma.net/es-mx/asbestos-en-elmundo.html

Chávez, P. (23 de Febrero de 2009). http://es.slideshare.net/. Obtenido de http://es.slideshare.net/:

http://es.slideshare.net/guest6c86df/convenio-de-rotterdam-julio2005

dec. $\mathrm{n}^{\circ}$ 154, 154 (Presidencia de la Republica Oriental de Uruguay 2002). 
Bio-grafía. Escritos sobre la Biología y su Enseñanza. ISSN 2027-1034

Número Extraordinario. p.p. 153-161

Memorias del Primer encuentro ambiental Universidad, ambiente y sustentabilidad: experiencias y prácticas.

Driscoll,T., et al. (2005). The global burden of disease due to occupational carcinogens. Obtenido de

http://www.who.int/quantifying_ehimpacts/global/2carcinogens.pdf

EITiempo, R. (24 de Octubre de 2014). Asbesto usado en Colombia no genera problemas de salud. Obtenido de

http://www.eltiempo.com/estilo-de-vida/salud/utilizacion-deasbesto-en-colombia/14733575

EITiempo, Redacciones. (24 de Febrero de 1999). La dificil batalla del Asbesto. El tiempo. Obtenido de http://www.eltiempo.com/archivo/documento/MAM-875041

GITICSA. (2009). GITICSA, tratamiento de residuos. Obtenido de GITICSA, tratamiento de residuos:

http://www.amianto.info/uso_industrial_del_amianto.html

Gromicko, N., Ward, E. (s.f.). La inspección del revestimiento de asbestocemento. Obtenido de https://www.nachi.org/asbestos-cementsiding-inspection-spanish.htm

2 Hess, A. (1 de Enero de 2000). Legislación argentina sobre el asbesto. Obtenido de http://www.estrucplan.com.ar/articulos/verarticulo.asp?IDArticulo=4 79

Ley N 656, 656 (Diario Oficial de la República de Chile, Santiago, Chile 2000).

Montes, I., et al. (2005). Normativa sobre el asbesto y sus enfermedades pleuropulmonares. Archivos de Bronconeumología, 41(3), 153168.

OMS. (2015). ASBESTO CRISOTILO. 2-3. Obtenido de http://www.who.int/:

http://www.who.int/ipcs/assessment/public_health/asbestos/es/

Proyecto de Ley 97, 97 (Imprenta Nacional de Colombia, Bogotá, Colombia, 2015. 2015). 